\title{
Incarcerated hiatal hernia after robot-assisted esophagectomy: transhiatal versus thoracoscopic approach
}

\author{
Judith Boone $\cdot$ Roy Jaap Jan Verhage • \\ Pieter Christiaan van der Sluis • \\ Richard van Hillegersberg
}

Published online: 13 October 2011

(c) The Author(s) 2011. This article is published with open access at Springerlink.com

With interest we read the article by Sutherland et al. [1] in which they reported their initial experience with transhiatal robot-assisted total esophagectomy in 36 patients with esophageal cancer. Seven (19.4\%) patients had postoperative incarcerated hiatal hernias and of those seven patients one died due to complications of the hernia repair. According to the authors, because the mediastinal dissection is done via laparoscopy, the hiatus is extensively dilated by the angles of the robotic arms, thereby increasing the risk of postoperative hiatal hernia. They therefore recommend performing a primary closure and reinforcement with mesh sutured to the gastric wall.

In 2009 we published the largest series of robot-assisted thoracolaparoscopic esophagectomies (RTE) [2]. We have performed this procedure in more than 140 patients. Minimally invasive esophagectomy substantially reduces blood loss and postoperative hospital and intensive care stay compared to open esophagectomy [3].

We adhere to the combined thoracic and abdominal approach to provide optimal oncological clearance. To date, the largest study that compares transhiatal with transthoracic surgery showed an important trend toward improved survival after transthoracic esophagectomy [4]. The survival benefit is attributed to a more extensive lymphadenectomy in the mediastinum. Furthermore, studies have shown that distal esophageal carcinomas

\footnotetext{
J. Boone

Department of Radiology, Amsterdam Medical Center, Amsterdam, The Netherlands

R. J. J. Verhage · P. C. van der Sluis · R. van Hillegersberg ( $\square)$ Department of Surgery, University Medical Center Utrecht, P.O. Box 85500, 3508 GA Utrecht, The Netherlands e-mail: R.vanHillegersberg@umcutrecht.nl
}

frequently metastasize to lymph nodes in the upper mediastinum [2, 5]

We have not experienced any postoperative hiatal hernias in our patients so far. In our opinion, this is the result of performing the mediastinal dissection of the esophagus and surrounding lymph nodes through thoracoscopy instead of through the diaphragm. During the laparoscopic phase of RTE, the stomach is mobilized, regional abdominal lymph nodes are dissected, and the esophagus is pulled out of the mediastinum. By performing the mediastinal dissection thoracoscopically, the integrity of the hiatus is preserved and no incarcerated hiatal hernias will be encountered postoperatively. In this way, the above-mentioned recommendation of the authors can be abandoned. We would encourage Sutherland et al. to continue performing robot-assisted esophagectomies and to experience the many advantages of the robot-assisted thoracoscopic approach.

Disclosures Drs R. J. J. Verhage and R. van Hillegersberg have received an unrestricted grant from Nycomed for an experimental study on healing of esophagogastric anastomoses. Drs J. Boone and P. C. van der Sluis have no conflicts of interest or financial ties to disclose.

Open Access This article is distributed under the terms of the Creative Commons Attribution Noncommercial License which permits any noncommercial use, distribution, and reproduction in any medium, provided the original author(s) and source are credited.

\section{References}

1. Sutherland J, Banerji N, Morphew J, Johnson E, Dunn D (2011) Postoperative incidence of incarcerated hiatal hernia and its prevention after robotic transhiatal esophagectomy. Surg Endosc 25:1526-1530 
2. Boone J, Schipper ME, Moojen WA, Borel Rinkes IH, Cromheecke GJ, van Hillegersberg R (2009) Robot-assisted thoracoscopic oesophagectomy for cancer. Br J Surg 96:878-886

3. Verhage RJ, Hazebroek EJ, Boone J, van Hillegersberg R (2009) Minimally invasive surgery compared to open procedures in esophagectomy for cancer: a systematic review of the literature. Minerva Chir 64:135-146

4. Omloo JM, Lagarde SM, Hulscher JB, Reitsma JB, Fockens P, van Dekken H, ten Kate FJ, Obertop H, Tilanus HW, van Lanschot JJ
(2007) Extended transthoracic resection compared with limited transhiatal resection for adenocarcinoma of the mid/distal esophagus: five-year survival of a randomized clinical trial. Ann Surg 246:992-1000

5. Schroder W, Monig SP, Baldus SE, Gutschow C, Schneider PM, Holscher AH (2002) Frequency of nodal metastases to the upper mediastinum in Barrett's cancer. Ann Surg Oncol 9:807-811 